\title{
The Effect of Priming on the Effectiveness of Threat Appeals
}

\author{
Birgit Wauters \\ Vrije Universiteit Brussel \\ E-Mail: birgit.wauters@vub.ac.be \\ Malaika Brengman \\ Vrije Universiteit Brussel \\ E-Mail: malaika.brengman@vub.ac.be
}

\begin{abstract}
Priming can be used to activate mental representations in an unobtrusive manner, so that these unconscious mental processes influence subsequent behaviour. A prime increases the accessibility of mental information regarding a primed issue. The objective of this article is to measure how positive versus negative priming influences the processing and effectiveness of threat appeals to promote flu shots. Threat appeals are used to warn people about a possible (health) risk and to convince them to adopt the recommended behaviour. Priming was found to have an impact on the respondents' feelings of severity and evoked fear. Also the broader environmental context was found to play an important role. This finding is interesting as it opens the door to create more effective threat appeals by controlling or influencing the affective context in which the threat appeal is displayed. An analysis of the processing patterns of the threat appeals showed that perceived severity, self and response efficacy have a positive effect on the behavioural intention to get a flu shot. This intention is also influenced by the evoked feelings of fear, which are induced by the respondents' perceived severity. This provides further proof to confirm the Extended Parallel Process Model. The core social implication of this research is for people who are engaged in preventing diseases or unhealthy behaviours and who use awareness campaigns to reach that goal.
\end{abstract}

Keywords: Social Marketing, Threat appeals, Affective priming, advertising design and effectiveness 


\section{INTRODUCTION}

A prime increases the accessibility of mental information regarding a primed issue (Mandel \& Johnson, 2002), which may influence subsequent behaviour. The objective of this article is to measure how positive or negative priming influences the effectiveness of threat appeals. Threat appeals are often used in social marketing campaigns to inform people about a possible (health) risk and to convince them to adopt recommended behaviour or to take preventive measures (Dillard \& Anderson, 2004; Duval \& Mulilis, 1999; La Tour \& Tanner, 2003). By describing the negative consequences of, in our study, a seasonal flu, social marketers try to convince the receiver of the message to take the preventive measure that is prescribed in the message (Witte, 1992). This study looks at the possible effect of priming on the effectiveness of threat appeals. As the immediate context of an ad is known to influence the perception of the information provided in the ad and its effectiveness (Choi \& Lin, 2007), we expect that a prime can activate negative or positive constructs (e.g., fear, worry, unhappiness versus ease of mind, feelings of stability) and these mental representations will influence the interpretation of the subsequent message and its information (e.g., a threat appeal message and its recommendation). We also expect that the wider environmental context of the receiver of the message may affect the interpretation and effectiveness of the message.

The contributions of this article are threefold. First of all, we test whether affective priming has an effect on the threat and efficacy appraisals. Moreover, we test whether the level of threat used in the threat message influences the effect of priming. At last, we examine whether the environmental context can influence the effect of priming on the effectiveness of threat appeals.

The remainder of this article is organized as follows. In the next section priming and its effects as well as the theory behind threat appeals are outlined concisely. The research objectives are explained in the subsequent section, followed by the hypotheses and the methodology. Finally, the results are reported and discussed.

\section{PRIMING}

Priming can be used to activate mental representations in an unobtrusive manner, so that these unconscious mental processes can influence subsequent behaviour (Harris, Bargh, \& Brownell, 2009). For a good overview of the history of, and a practical guide to priming, interested readers are referred to Bargh and Chartand 
(2000). Priming is thought to operate as a kind of overlap or association between the mental representations activated by 'the prime' and those representations used to enact certain behaviour (Dijksterhuis \& Bargh, 2001). The prime thus increases the accessibility of the mental information regarding a certain issue (Mandel \& Johnson, 2002). Next to 'semantic priming' (word associations e.g., the word dog triggers the word cat) and 'feature priming' (the prime is associated with a specific feature and this will have its effect on the subsequent evaluation (Mandel \& Johnson, 2002)), the priming used in this article is 'affective priming'; whereby someone's judgement of a person, product or object is influenced by the emotional constructs that are activated in an earlier task $(\mathrm{Yi}, 1990)$. This means that if one reads a sad story this will trigger negative, depressing feelings as an affective reaction, which may influence subsequent appraisals.

\section{THREAT APPEALS}

Threat appeals contribute to raising awareness about unhealthy behaviours or potential dangers (Lewis, Watson, Tay, \& White, 2007; Miles, Rapoport, Wardle, Afuape, \& Duman, 2001). They are often used in social marketing campaigns to inform people about a possible (health) risk and to convince them to adopt recommended behaviour or to take preventive measures (Dillard \& Anderson, 2004; Duval \& Mulilis, 1999; La Tour \& Tanner, 2003). By describing the negative consequences of certain risky actions (e.g., lung cancer for smokers), social marketers try to convince the receiver of the message to adopt the change in behaviour or lifestyle that is prescribed in the message (Witte, 1992). Numerous academics have proposed different theories to explain the process through which threat appeals motivate behavioural change (Janis, 1967; Leventhal, 1971; Rogers, 1975; Witte, 1992). According to these theories two parallel message appraisals occur when someone is exposed to a threat appeal message: (1) 'threat appraisal' and (2) 'efficacy appraisal'. 'Threat appraisal' involves the assessment of (i) the 'severity' of the threat (i.e., how severe are the negative consequences) and (ii) the 'susceptibility' to the threat (i.e., how vulnerable am I to this threat). Someone has to perceive the threat as severe and to be at risk for it in order for the threat appeal to produce sufficient fear to motivate a change in behaviour. 'Efficacy appraisal' or coping appraisal involves the assessment of (i) 'response efficacy' (i.e., the belief that the recommended behaviour is actually effective to avert the threat) and (ii) 'self efficacy' (i.e., the belief to be able to perform the recommended behaviour yourself). 


\section{RESEARCH OBJECTIVES}

The objective of this article is to measure whether positive versus negative priming influences the effectiveness of threat appeals to promote flu shots. A first aim is to examine whether affective priming has an effect on the threat and efficacy appraisals, on feelings of fear and on the intention to perform the recommended behaviour. Another goal is to test whether the level of threat used in the threat message influences the effect of priming. As a third research objective, we want to examine whether the environmental context influences the effect of priming on the effectiveness of threat appeals.

\section{Hypotheses}

A meta-analysis conducted by Witte and Allen (2000), which synthesized more than 100 threat appeal articles, "additionally found empirical support for the fact that the four message components (i.e., severity, susceptibility, response efficacy and self efficacy) produce positive persuasive effects" (p. 602-603). These findings were in line with the Extended Parallel Process Model and give support for the following hypotheses:

H1: The intention to get a flu shot will be positively influenced by (a) perceived severity, (b) perceived susceptibility, (c) response efficacy and (d) self efficacy as well as by (e) the evoked feelings of fear.

H2: Evoked fear will be positively influenced by (a) perceived severity, (b) perceived susceptibility and negatively by (c) response and (d) self efficacy.

The Extended Parallel Process Model (Witte, 1992) suggests that if a person does not find the presented danger seriously threatening, a confrontation with the threat appeal will not result in following the recommended behaviour to avert that specific threat (Wong \& Cappella, 2009). Increasing the level of the presented threat should lead this person to find the threat more severe, which may make the message more effective. De Hoog, Stroebe \& de Wit (2005) also claim that message involvement is higher when messages with a high threat level are used. It is therefore possible that the respondent will also feel more vulnerable to the threat presented in the message (i.e., more susceptible) when the presented threat level is higher.

H3: A threat appeal displaying more severe consequences of a seasonal flu leads to (a) increased perceived severity and (b) increased perceived susceptibility 
in comparison to a threat appeal portraying less threatening consequences of this flu.

H4: A threat appeal displaying more severe consequences of a seasonal flu leads to (a) increased evoked fear and (b) a higher intention to get a flu shot in comparison to a threat appeal portraying less threatening consequences of this flu.

As the context of an ad is known to influence the perception of the information given in the ad and its effectiveness (Yi, 1990), we expect that a prime can activate negative or positive constructs (e.g., fear, worry, unhappiness versus ease of mind, feelings of stability) and that these mental representations will influence the interpretation of the subsequent message and its information (e.g., a threat appeal message and its recommendation). Affective priming has been demonstrated to be able to influence an advertisement's effectiveness, as researchers (Yi, 1990) found that a negatively toned prime will influence a persons' attitude towards the message and also his purchase intention (PI) in a negative way. When the tone of the prime was positive the subjects rated PI significantly higher.

In our study the intention to perform the recommended behaviour after seeing a threat appeal message will presumably be higher after seeing a negatively primed newspaper article than after seeing a positive one. However, we do anticipate some compensating effects. First of all, we expect that the perceived severity and susceptibility will be higher after seeing a prime with a negative tone, leading towards an increased intention to get a flu shot. On the other hand, we expect that a negative prime also causes a lower self and response efficacy, which may reduce the intention to get a flu shot. However, given the fact that in general more weight is attached to negative information and people are known to be more responsive to negative information as compared to positive information (Kahneman \& Tversky, 1979, 1984; Pratto \& John, 1991), we assume that the perceived severity and susceptibility will have more impact on the intention towards getting a flu shot.

H5: Perceived severity (a) and susceptibility (b) will be higher after seeing a prime with a negative affective tone than after seeing a prime with a positive affective tone and response efficacy (c) and self efficacy (d) will be lower.

H6: The evoked fear (a) and the intention to get a flu shot (b) will be higher after seeing a prime with a negative affective tone than after seeing a prime with a positive affective tone. 
Moreover, we expect that the negative (versus positive) prime will reinforce the impact of threat intensity on the effectiveness of the threat appeal.

H7: A threat appeal displaying more severe (versus less severe) consequences of a seasonal flu combined with a negative (versus positive) prime leads to (a) increased perceived severity, (b) increased perceived susceptibility, (c) decreased response efficacy and (d) decreased self efficacy.

H8: The feelings of evoked fear (a) and the intention to get a flu shot (b) will be higher when a threat appeal displaying more severe (versus less severe) consequences of a seasonal flu is combined with a negative (versus positive) prime.

We also believe that the environmental context can influence the impact of priming on the effectiveness of threat appeals. Differences in the effectiveness of threat appeals between different nationalities have already been demonstrated (e.g., Laroche et al. found that a physical threat appeal had more effect on Anglo than on Chinese respondents (2001)). We are convinced that a prime congruent environmental context can reinforce the effect of the prime, while a prime incongruent environmental context will reduce or eliminate its effect.

H9: Perceived severity (a) and susceptibility (b) will be higher (respectively lower) and response efficacy (c) and self efficacy (d) will be lower (respectively higher) among respondents seeing a prime with a negative (respectively positive) affective tone in a congruent environmental context than after seeing the prime in an incongruent environmental context.

H10: Evoked fear (a) and the intention to get a flu shot (b) will be higher among respondents seeing a prime with a negative (respectively positive) affective tone in a congruent environmental context than after seeing the prime in an incongruent environmental context.

\section{METHODOLOGY}

\section{Design and Stimuli}

A between subjects full factorial $2 \times 2 \times 2$ experimental design was constructed (level of threat $\mathrm{x}$ affective prime $\mathrm{x}$ environmental context). Two threat appeal messages were designed to promote getting a flu shot, differing in the level of threat [level of threat: low/high] and presented with different affective primes [priming: negative/positive]. The last factor pertained to the environmental context 
[environmental context: more prime congruent/less prime congruent].

The health risk chosen for the threat message (Figure 1) was the hypothetical seasonal flu RNA5, which could be lethal (i.e., high threat level) or just unpleasant like any other seasonal flu (i.e., low threat level). This chosen topic should be of interest to anyone, as everybody can get a seasonal flu and given that the data was collected during the winter period, the flu and its negative consequences were relevant at that period in time. Also the preventive action against such a seasonal flu is getting a flu shot, which is inexpensive, effective, accessible and easily to obtain. The baseline of the message read 'Did you already get your flu shot?', a text emphasizing the self and response efficacy stated 'A simple flu shot can help you through this winter without getting the flu. Contact your GP or go to www.influenza.com to get more information' and the recommendation was formulated in the slogan 'Get Vaccinated'.
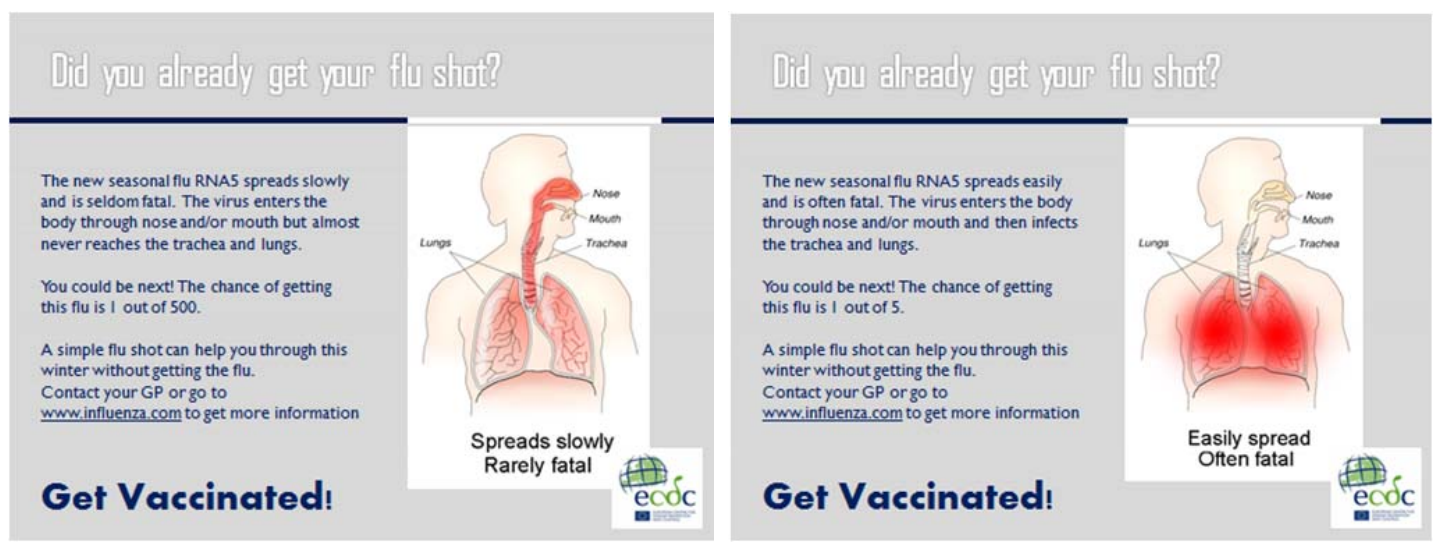

Figure 1 Low Level Threat Appeal (First) and High Level Threat Appeal (Second)

A distinction was made between two levels of threat. For the high threat condition, a picture of the human respiratory system was displayed, with the lungs highlighted in red with the text 'easily spread, often fatal' underneath. For the low threat condition no parts of the respiratory system were highlighted and the text below read 'spreads slowly, rarely fatal'. Thus, the high fear evoking threat message presented a severe seasonal flu, which spreads easily and is often fatal. The virus enters the body through nose and/or mouth and then infects the trachea and lungs. It stated: You could be next! The chance of getting this flu is 1 out of 5. The low fear evoking message contained the text: The new seasonal flu RNA5 spreads slowly and is seldom fatal. The virus enters the body through nose and/or mouth but almost never reaches the trachea and lungs. It stated: You could be next! The chance of getting this 
flu is 1 out of 500 .

To differentiate between the positive and negative priming, a newspaper article Figure 2 was constructed, either with a negative or positive state of the current economy, accompanied by some key words in a word cloud (Figure 3) consisting of words related to either economic growth (e.g., growth, job stability, wealth...) or recession (e.g., crisis, unemployment, poverty...).

\section{Economic growth expected of $2.2 \%$}

Europe expects the economy in 2012 will grow by 2.2 percent. The number of unemployed people will continue to decline, according to the report "Economic Perspectives 2011-2016." The growth forecast of 2.2 percent for the economy would be accompanied by an estimated 43,000 new jobs this year and an average of 48,000 during the period 2012-2016.

This growth is also positive for hundreds of thousands of families who will get a more favorable mortgage rate making the purchase and payment of houses substantially more accessible to everyone. Also will the additional wage increases give families more financial leeway.

The improved performance is due to more export and rising consumption. That consumption dropped after the earthquake and tsunami of March 11 to an all time low. (Belga / sam)

\section{Economic downturn expected of $2.2 \%$}

Worldwide 23 million people extra can end up in poverty due to the economic crisis in the rich countries, and especially in case of a recession in Europe. That is stated by the International Monetary Fund in a report. According to calculations by the IMF there will be in such a scenario "severe impacts on poverty."

By 2012 there will be 23 million additional people finding themselves in poverty. Hundreds of thousands of families are in danger of getting into trouble in the coming years when their current beneficial mortgage rate expires and at the same time various cuts must be undertaken.

Unemployment continues to rise so that current school leavers have minimal chances to get started immediately. A whole generation seems to be doomed by this economic crisis. (Belga/ sam)

Figure 2. Newspaper articles used for priming (first: positive and second: negative) 


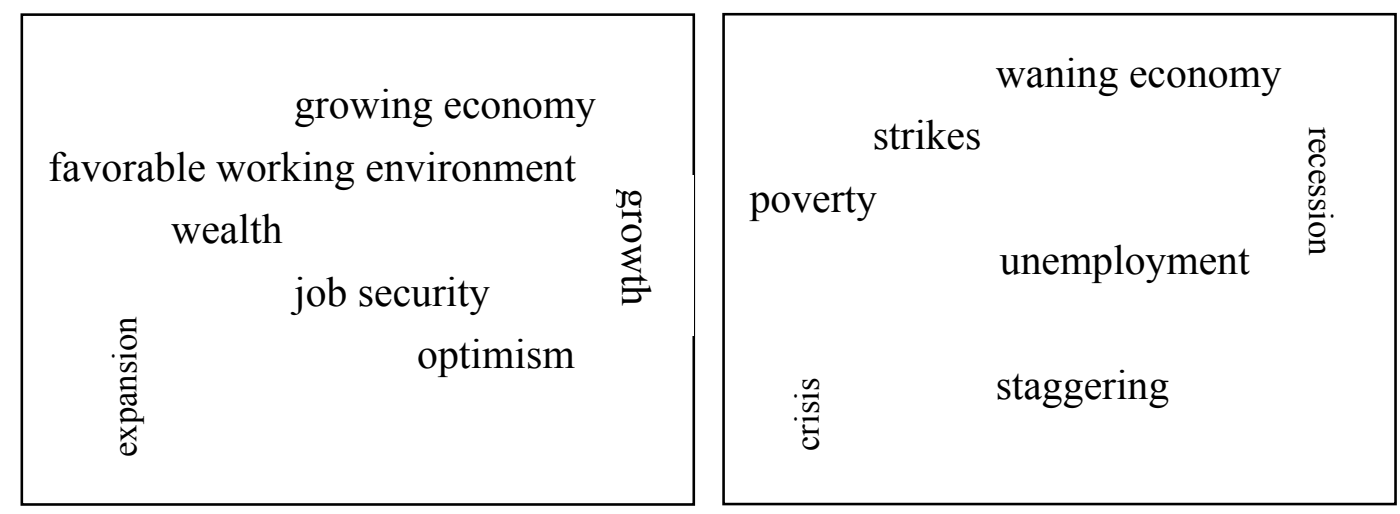

Figure 3: The Word Clouds Used for Priming (Left Positive and Right Negative)

As for the environmental context we chose two countries, namely Greece and Belgium. Both countries experience consequences of the current economic crisis in Europe, but the implications of the crisis for the Greek population are far more severe than for the Belgian population and we expect that this could have an impact on the perception of the prime and the threat appeals. Given the current economic situation in Greece, which has vast detrimental consequences for the Greek population, we expect that the environmental context for the Greeks is more congruent with the negative prime in our study than for the Belgians. For the Belgian respondents the consequences of the economic crisis are milder, thus the environmental context is deemed less congruent with the negative prime in our study. Therefore, we expect to find differences between both populations as an effect of the congruency with the broader environmental context in which the priming takes place (Yi, 1990).

Another important reason to pick those two populations, is the fact that data from the World Health Organization show that both countries reported influenza amongst their citizens, going from a low intensity in December 2011 (meaning: no influenza activity or influenza at baseline levels) to a very high level of intensity in March 2012 (particularly severe levels of influenza activity). Both Greece and Belgium reported the highest and lowest intensity of the seasonal flu in the same weeks with almost comparable influenza-like illness rates (World Health Organization, 2012). That means that both populations are equally vulnerable to the presented threat. Another contributing factor for the selection of both countries is their scores on Hofstede's national cultural index for uncertainty avoidance (Hofstede, 2012b). Both countries score in the top section with respect to uncertainty avoidance, indicating that both do not feel at ease with uncertainty, ambiguity and want to control the future (Hofstede, 2012a). Translated to our study, this means that, apart from the priming conditions, both populations are expected to react similarly to the threat stimuli and to be equally 
prone to get a flu shot.

\section{Measures}

The Risk Behaviour Diagnosis Scale (RBDS) (Witte, McKeon, Cameron, \& Berkowitz, 1995) was used in this research to measure the respondents' perceived severity \& susceptibility and self \& response efficacy. The RBDS consists of two items $^{1}$ for perceived susceptibility $(\mathrm{r}=.529, \mathrm{n}=521, \mathrm{p}<.001)$ and three items for perceived severity ( $\alpha=.863)$, three items for self efficacy $(\alpha=.804)$ and three items for response efficacy $(\alpha=.840)$, each rated on five point Likert type scales. We also included a measure for the amount of fear that is evoked by the message (evoked fear, $\alpha=.901$, four items, based on Keller and Block (1996)). The respondents were asked to rate on a semantic differential 'How did the statements of the health message make you feel?' (very unafraid/ very afraid, relaxed/tense,...). The intention to get a flu shot was also rated on a five point Likert type scale based on Ajzen and Fishbein (1980) ( ix items; $\alpha=.921$ ). Credibility (three items; $\alpha=.790$, based on Block and Keller (1995)) was used as a covariate to control for the possibility that some respondents found the information in the message less credible. The questions in the questionnaire were translated with back-translation into Dutch and Greek.

\section{Participants and Procedure}

A convenience sample of 521 respondents (297 females, 57\%, 252 Greeks, $48.4 \%$ ), with a mean age of 27 years (min. 18, max. 63) participated in our study. They responded to an e-mailed invitation with a link to the online questionnaire that was programmed in Limesurvey. According to a number picked by the respondents (1-4), they either saw the negative or positive prime and the low or high level threat appeal. After seeing these stimuli the respondents were asked to fill in the questionnaire, which was provided in their own language. The survey was online from the end of December until mid-March (2011-2012) as this period is known for its annual seasonal influenza peak.

\section{RESULTS}

The processing patterns were analysed by means of partial least squares (PLS) (Ringle, Wende, \& Alexander, 2005). The rules of thumb for sample size (1998) were obtained, because the sample consisted of 521 respondents. Hence, this sample size

\footnotetext{
1 The original scale consists of 3 items for perceived susceptibility but factor analysis and scale reliability indicated that one item (It is likely that I will get the seasonal flu) had to be deleted.
} 
can be seen as sufficient to obtain stable estimates (Chin, 1998). The quality criteria are listed in Table 1. The communalities, as indicated by Höck and Ringle (2006), all exceeded 0.70 . The composite reliabilities also were acceptable because they all exceeded 0.80 (Höck \& Ringle, 2006). The Cronbach alpha values were considered acceptable because each of them exceeded 0.60 . The coefficient of determination $\left(\mathrm{R}^{2}\right)$ was used to measure the overall size of the effect in the model. The value of $\mathrm{R}^{2}$ was $7.4 \%$ for evoked fear and $18.6 \%$ for intention. The structural model is shown in Figure 4. The results are shown in Table 2 . Five paths are significant: from perceived severity to evoked fear $(\beta=.247, \mathrm{p}<.001)$, from perceived severity to intention $(\beta=.233, \mathrm{p}$ $<.001)$, from self efficacy to intention $(\beta=.118, \mathrm{p}=.004)$, from response efficacy to intention $(\beta=.152, \mathrm{p}=.017)$ and finally evoked fear also has a significant impact on intention $(\beta=.085, p=.067)$, confirming all hypotheses except for H2b-d and H1b.

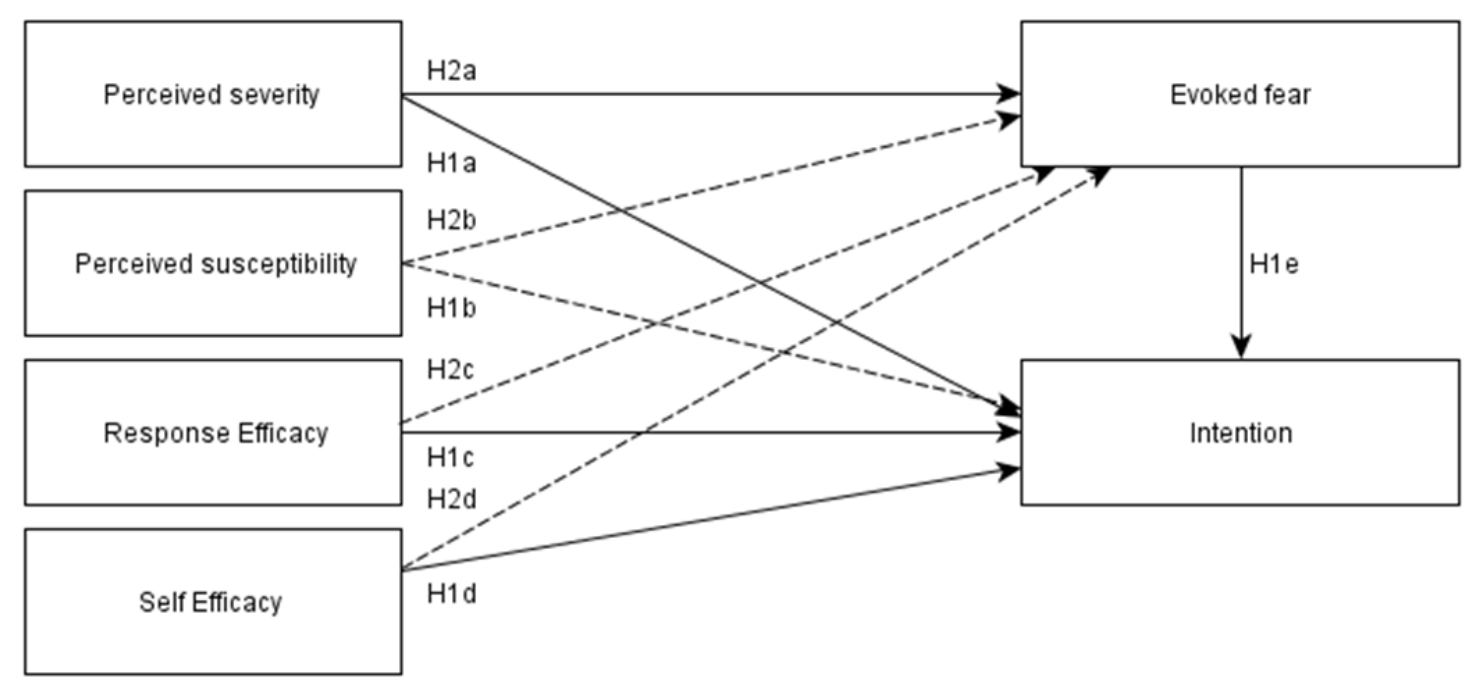

Figure 4 Measurement Results, The Dotted Lines are Non-Confirmed Hypotheses; The Full Lines are Confirmed Hypotheses. 
Table 1 Overview of the Constructs’ Reliability and Model Quality Indicators

\begin{tabular}{lcccccc}
\hline & AVE & $\begin{array}{c}\text { Composite } \\
\text { Reliability }\end{array}$ & $\begin{array}{c}\mathrm{R} \\
\text { Square }\end{array}$ & $\begin{array}{c}\text { Cronbachs } \\
\text { Alpha }\end{array}$ & Communality & Redundancy \\
\hline $\begin{array}{l}\text { Perceived } \\
\text { Susceptibility }\end{array}$ & 0,758 & 0,862 & & 0,692 & 0,758 & \\
\hline Perceived Severity & 0,784 & 0,916 & & 0,862 & 0,784 & \\
\hline Self Efficacy & 0,717 & 0,884 & & 0,804 & 0,717 & \\
\hline Response Efficacy & 0,756 & 0,903 & & 0,840 & 0,756 & \\
\hline Evoked Fear & 0,768 & 0,929 & 0,074 & 0,899 & 0,768 & 0,051 \\
\hline Intention & 0,759 & 0,940 & 0,186 & 0,920 & 0,759 & 0,017 \\
\hline
\end{tabular}

Table 2 Standardized Loadings $\mathrm{p}<.10^{\Phi} \mathrm{p}<.05^{*} \mathrm{p}<.01 * * \mathrm{p}<.001 * * *$

\begin{tabular}{lcc}
\hline & Intention & Evoked fear \\
\hline Perceived susceptibility & 0,045 & 0,049 \\
\hline Perceived severity & $0,233^{* * *}$ & $0,247^{* * *}$ \\
\hline Self efficacy & $0,118^{* *}$ & 0,014 \\
\hline Response efficacy & $0,152^{* *}$ & 0,028 \\
\hline Evoked fear & $0,085^{\mp}$ & \\
\hline
\end{tabular}

A MANCOVA analysis was performed with level of threat, affective priming and environmental context as fixed factors and credibility as a covariate (see Table 3 for results). The Greek respondents found the threat appeal to be less credible than the Belgian respondents $\left(\mathrm{M}_{\text {Greek }}=3.192, \mathrm{SD}_{\text {Greek }}=.822\right.$ vs. $\mathrm{M}_{\text {Belgian }}=2.181, \mathrm{SD}_{\text {Belgian }}=.749$, $\mathrm{t}(519)=-5.503, \mathrm{p}<.001)$ and the high level threat appeal was also found less credible than the low level threat appeal $\left(\mathrm{M}_{\text {low }}=2.914, \mathrm{SD}_{\text {low }}=.795\right.$ vs. $\mathrm{M}_{\text {high }}=3.120$, $\left.\mathrm{SD}_{\text {high }}=.810, \mathrm{t}(519)=-2.897, \mathrm{p}=.004\right)$. Given these differences it is recommended to control for the credibility of the message. Significant main effects are found for level of threat: respondents' perceived severity was higher after seeing the high threat level compared to the low $\left(\mathrm{M}_{\text {low }}=2.648\right.$ vs. $\left.\mathrm{M}_{\text {high }}=2.865, \mathrm{p}=.008\right)$, confirming H3a. Also their evoked fear was marginally significantly higher after seeing the high threat stimulus $\left(\mathrm{M}_{\text {low }}=2.145\right.$ vs. $\left.\mathrm{M}_{\text {high }}=2.289, \mathrm{p}=.080\right)$, confirming H4a. The same main effects are found for the priming condition: a higher perceived severity is perceived after seeing a negative prime $\left(\mathrm{M}_{\text {neg }}=2.845\right.$ vs. $\left.\mathrm{M}_{\text {pos }}=2.668, \mathrm{p}=.029\right)$, confirming H5a. However, the significant two-way interaction effect found between environmental context and priming, see Figure 5, indicating that this previous main effect is not straight forward. Priming did not cause a difference in perceived severity for the 
Belgian respondents, but only for the Greeks. For the Greek respondents (more prime congruent environmental context), seeing a negative prime caused more feelings of severity towards the threat compared to the positive prime, whereas the perceived severity of the Belgian respondents appeared to be a lot higher in general but not influenced by the priming condition $\left(\mathrm{M}_{\text {Greek neg }}=2.284\right.$ vs. $\mathrm{M}_{\text {Greek pos }}=2.590, \mathrm{M}_{\text {Belgian }}$ ${ }_{n e g}=3.189$ vs. $M_{\text {Belgian pos }}=3.185, p=.032$ ). Still, another main effect of priming was found on evoked fear; more feelings of fear were reported after seeing the negatively primed message $\left(\mathrm{M}_{\text {neg }}=2.296\right.$ vs. $\left.\mathrm{M}_{\text {pos }}=2.139, \mathrm{p}=.053\right)$, confirming H6.

The environmental context of the respondents actually appeared to influence all the threat and efficacy appraisals as well as the intention to perform the recommended behaviour. Belgian respondents appeared to feel more susceptible to the threat $\left(\mathrm{M}_{\text {Greek }}=2.164\right.$ vs. $\left.\mathrm{M}_{\text {Belgian }}=2.420, \mathrm{p}<.001\right)$ and found the threat of the flu more severe $\left(\mathrm{M}_{\text {Greek }}=2.327\right.$ vs. $\left.\mathrm{M}_{\text {Belgian }}=3.187, \mathrm{p}<.001\right)$ compared to the Greek respondents. Next to this, the data reveal that the efficacy appraisals of the Belgian respondents were higher than those of the Greek respondents; self efficacy $\left(\mathrm{M}_{\mathrm{Greek}}=2.978\right.$ vs. $\mathrm{M}_{\text {Belgian }}=3.467$, $\mathrm{p}<.001)$ and response efficacy $\left(\mathrm{M}_{\text {Greek }}=3.185\right.$ vs. $\left.\mathrm{M}_{\text {Belgian }}=3.627, \mathrm{p}<.001\right)$. As a logical result the Belgian respondents had a higher intention to get a flu shot compared to the Greeks $\left(\mathrm{M}_{\text {Greek }}=2.284\right.$ vs. $\left.\mathrm{M}_{\text {Belgian }}=2.590, \mathrm{p}<.001\right)$. No significant differences in feelings of evoked fear were found between Greek and Belgian respondents.

Table 3 MANCOVA Results with Credibility as Covariate

\begin{tabular}{|c|c|c|c|c|c|c|c|c|c|}
\hline & \multicolumn{2}{|c|}{ Level of threat } & \multicolumn{3}{|c|}{ Priming } & \multicolumn{4}{|c|}{$\begin{array}{l}\text { Environmental } \\
\text { context }\end{array}$} \\
\hline & Low & High & & Negative & Positive & & Greek & Belgian & \\
\hline & M & M & $\begin{array}{c}\mathrm{p} \\
\text { value }\end{array}$ & M & M & $\begin{array}{c}\mathrm{p} \\
\text { value }\end{array}$ & M & M & $\begin{array}{c}\mathrm{p} \\
\text { value }\end{array}$ \\
\hline $\begin{array}{l}\text { Perceived } \\
\text { Severity }\end{array}$ & 2.648 & 2.865 & .008 & 2.845 & 2.668 & .029 & 2.327 & 3.187 & $<.001$ \\
\hline $\begin{array}{l}\text { Perceived } \\
\text { Susceptibility }\end{array}$ & 2.293 & 2.290 & .963 & 2.312 & 2.271 & .419 & 2.164 & 2.420 & $<.001$ \\
\hline $\begin{array}{l}\text { Response } \\
\text { Efficacy }\end{array}$ & 3.358 & 3.454 & .214 & 3.417 & 3.395 & .781 & 3.185 & 3.627 & $<.001$ \\
\hline Self Efficacy & 3.195 & 3.250 & .510 & 3.236 & 3.209 & .733 & 2.978 & 3.467 & $<.001$ \\
\hline Evoked Fear & 2.145 & 2.289 & .080 & 2.296 & 2.139 & .053 & 2.170 & 2.265 & .259 \\
\hline Intention & 2.383 & 2.492 & .231 & 2.499 & 2.375 & .169 & 2.284 & 2.590 & $<.001$ \\
\hline
\end{tabular}




\section{Perceived Severity}

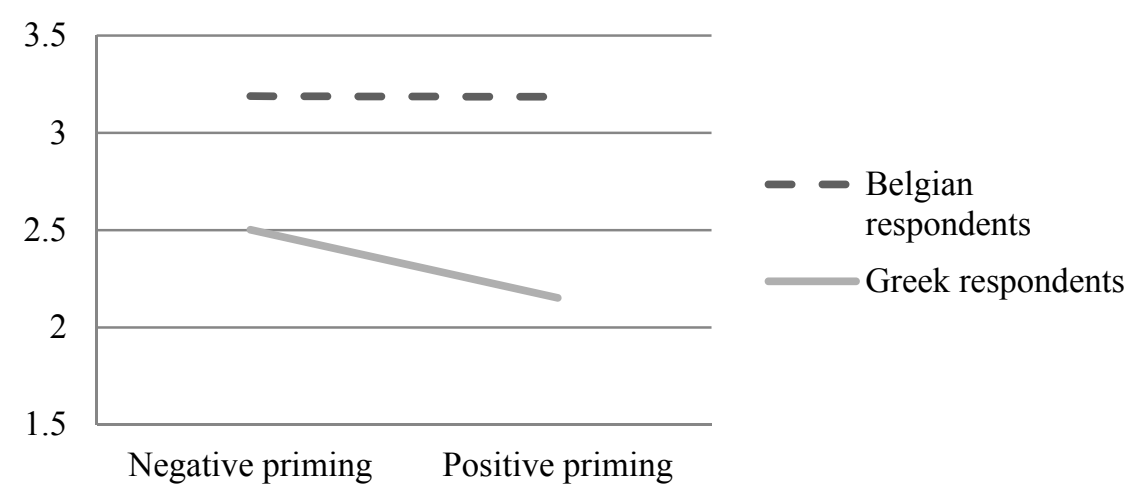

Figure 5 Interaction Effect between Priming and Environmental Context on Perceived Severity

\section{DISCUSSION}

The respondents' processing patterns of the threat messages were analysed to find out which of the elements of the Extended Parallel Process Model had an effect on the intention to get a flu shot. Perceived susceptibility did not have any effect, neither on feelings of evoked fear nor on intention, which was unexpected, but could be due to the fact that the measure did not have enough variance to exert effects statistically.

Nonetheless, significant relations are found between the other threat appraisal (i.e., perceived severity) as well as both the efficacy appraisals and the intention to get a flu shot, which is in line with previous research and partly confirms the EPPM (Witte \& Allen, 2000). Another significant path was found between perceived severity and evoked fear, confirming that if one finds the threat severe, the respondent will experience more feelings of fear. The evoked fear supplementary affects the intention to get a flu shot. This underlines the importance of evoking some fear amongst receivers of threat messages in order to persuade people into preventing diseases like flues.

Based on the findings of the MANCOVA, it can be concluded that priming can play a role in the effectiveness of threat appeals. The context in which such a message is displayed is thus important to ensure that the goal of the threat appeal is reached. The results show that affective priming can influence the perceived severity of a received threat in such a way that a negative prime (in our research concerning the bad economic status of a country), caused people to find the threat of a seasonal flu more severe. A significant two way interaction shows however that this effect needs to be 
nuanced as priming did not cause a difference in perceived severity for the Belgian respondents, but only for the Greek ones. The fact that perceived severity among the Belgians was already high in the positive priming condition could explain the fact that no increase in severity could be detected for the negative priming condition. The threat appeal message also evoked more feelings of fear when seen after a negatively primed message about the economic situation than when seen after a positively primed message about the economic position a country is in. As previous research already came across the finding that the immediate context in which a message is conveyed is of importance to influence the perception of an ad (Yi, 1990), we can conclude that this is also the case for threatening messages aimed at preventing diseases, like a seasonal flu, as one of the threat appraisals seems to be affected by a previous exposure to an affective prime.

Next to testing whether priming has an effect on the perception of a threat appeal, we also wanted to find out whether the level of threat used in the threat message influences the effect of priming. Previous research showed that increasing the amount of threat in a persuasive message made the message more effective as the severity and the susceptibility of the receiver augment when a more serious threat is presented (de Hoog et al., 2005). Therefore it was assumed in this article that combining a higher threat (but still not extreme to prevent fear control) with a negative prime would increase the perceived severity and susceptibility of the receiver even more. Looking at the combined effects of priming and threat level on the threat appraisals, we see that a threat appeal with a negative prime (versus a positive one) leads to increased perceived severity for both the low and high threat level conditions. But no significant reinforcing effect could be revealed. The results only show a significant main effect of level of threat on perceived severity and evoked fear, meaning that if a respondent was confronted with a high threat message he or she found the threat of the seasonal flu more severe and experienced more feelings of fear than when confronted with a milder threat, regardless of the prime. This is in line with previous research about the effectiveness of threat appeals (de Hoog et al., 2005; Witte, 1992). The main effects of priming on perceived severity and evoked fear revealed above are therefore established for low level as well as for high level threat appeals.

No reinforcing or interacting effects of priming and level of threat were found on the efficacy appraisals either. We assumed to find an increased believe of the respondents' own capabilities to do something about the threat of a seasonal flu if they were confronted with a positive prime. We also expected that the response efficacy would increase. But this did not appear to be the case. A possible explanation could be 
that the respondents are familiar with seasonal flus and know that a flu shot is an effective way to prevent this virus and that they feel capable enough to get such a flu shot, leaving little room for improvement regardless of how the message is primed. Looking at the high scores of both efficacy appraisals (for response efficacy the minimum mean score amounts to 3.2 on a 5-point scale and for self efficacy the lowest mean score equals 3 ) this explanation is very likely.

The next contribution of this paper is situated in detecting possible differences depending on the environmental context of respondents (Greek versus Belgian respondents). Those countries are chosen for this research because they both experience the consequences of the financial crisis occurring in Europe, but they are different due to the fact that the Greeks experience far more severe costs of this crisis than the people living in Belgium. In line with the priming story, the living conditions can be seen as a broader environmental context according to which the perception and effectiveness of a message can differ. Looking at the results of the study, we see that Greek respondents feel less threatened by the message than Belgian respondents, and the latter also indicate to have higher efficacy appraisals. In line with those findings, the intention to get a flu shot is also higher for the Belgian respondents, which is logical given the fact that they experience the threat as more severe, find themselves susceptible to the threat and also capable of doing something about the threat (Witte \& Allen, 2000). In this study, a significant interaction effect could be revealed between the prime and the environmental context. Priming apparently only seemed to affect the perceived severity of the Greek respondents and not the Belgian ones, which points to the importance of considering this broader context when looking at the impact of priming and threat appeals.

\section{CONCLUSIONS, IMPLICATIONS AND SUGGESTIONS FOR FURTHER RESEARCH}

A prime can be used to increase the approachability of mental information regarding the primed topic (Mandel \& Johnson, 2002) and this may influence subsequent information processing and behaviour. The objective of this article was to measure how positive or negative priming influences the effectiveness of threat appeals. Priming was found to have an impact on the respondents' feelings of severity and feelings of fear evoked by a subsequent threat message and this regardless of the intensity of the presented threat. This finding could be interesting as this opens the door to create more effective threat appeal messages by controlling or influencing the affective context in which a threat appeal is presented to a person. The analysis of the 
processing patterns of the threat appeals showed that perceived severity and self and response efficacy do have a positive effect on the intention to get a flu shot. This intention is also influenced by the evoked feelings of fear, which are induced by the respondents' appreciation of the severity of the given threat. This pattern of processing provides further proof to confirm the EPPM (Witte, 1992).

The core social implication of this research is for people who are engaged in preventing diseases or unhealthy behaviours and who use awareness campaigns to reach that goal. Governments and non-profit organizations can use this study to create effective threat appeals in order to augment the knowledge concerning the dangers of certain viruses and to persuade people to take preventive measures or stop an unhealthy lifestyle. By priming people, the messages can be made more persuasive. A prime can set the receiver of the message in the right state of mind to increase the effectiveness of the message. Further research should focus on the best way to prime people and on the impact of the environmental context or other potential individual differences. Priming appeared to cause differences in perceived severity, but only for the Greeks and not for the Belgians. It is possible that other individual characteristics also cause a different perception of the prime and thus influence the impact of the prime and the effectiveness of the subsequent message. These issues remain to be investigated further.

\section{REFERENCES}

Ajzen, I., \& Fishbein, M. (1980). Understanding attitudes and predicting social behavior. EnglewoodCliffs, NY: Prentice Hall.

Bargh, J., \& Chartrand, T. (2000). The mind in the middle: a practical guide to priming and automaticity research. In H. T. Reis \& C. M. Judd (Eds.), Handbook of Research Methods in Social and Personality Psychology - Harry T. Reis, Charles M. Judd - Google Boeken (pp. 253-285). New York: Cambridge University Press.

Block, L. G., \& Keller, P. A. (1995). When to accentuate the negative: the effects of perceived efficacy and message framing on intentions to perform a health related behavior. Journal of marketing research, 32(2), 192-203. http://dx.doi.org/10.2307/3152047.

Chin, W. W. (1998). The partial least squares approach to structural equation modeling. In G. A. Marcoulides (Ed.), Modern methods for business research (pp. 295-358). Mahwah: NJ, US: Lawrence Erlaum Associates.

Choi, Y., \& Lin, Y.-H. (2007). Communicating Risk: the effects of message appeal 
and individual difference on risk message processing. Paper presented at the International Communication Association, San Francisco.

de Hoog, N., Stroebe, W., \& de Wit, J. B. F. (2005). The impact of fear appeals on processing and acceptance of action recommendations. Personality and social psychology bulletin, 31(1), 24-33. http://dx.doi.org/10.1177/0146167204271321.

Dijksterhuis, A., \& Bargh, J. A. (2001). The perception-behavior expressway: Automatic effects of social perception on social behavior. Advances in $\begin{array}{llll}\text { Experimental Social } & \text { Psychology, } & 33, & 1-40 .\end{array}$ http://dx.doi.org/10.1016/S0065-2601(01)80003-4.

Dillard, J. P., \& Anderson, J. W. (2004). The role of fear in persuasion. psychology \& marketing, 21(11), 909-926. http://dx.doi.org/10.1002/mar.20041.

Duval, T. S., \& Mulilis, J.-p. (1999). A person-relative-to-event (PrE) approach to negative threat appeals and earthquake preparedness: a field study. Journal of $\begin{array}{llll}\text { applied social } & \text { 29(3), }\end{array}$ http://dx.doi.org/10.1111/j.1559-1816.1999.tb01398.x.

Harris, J. L., Bargh, J. A., \& Brownell, K. D. (2009). Priming effects of television food advertising on eating behavior. Health psychology, 28(4), 404-413. http://dx.doi.org/10.1037/a0014399.

Hofstede, G. (2012a). Dimensions. Retrieved June, 13 2012, from http://geert-hofstede.com/dimensions.html.

Hofstede, G. (2012b). National Culture - Countries. Retrieved une, 13 2012, from http://geert-hofstede.com/countries.html.

Höck, M., \& Ringle, C. M. (2006). Strategic networks in the software industry: an empirical analysis of the value continuum. Paper presented at the IFSAM VIIIthe World Congress, Berlin.

Janis, I. (1967). Effects of fear arousal on attitude change: Recent developments in theory and experimental research. Advances in experimental social psychology, 3, 166-225. http://dx.doi.org/10.1016/S0065-2601(08)60344-5.

Kahneman, D., \& Tversky, A. (1979). Prospect theory: An analysis of decision under risk. Econometrica, 47(2), 263-291. http://dx.doi.org/10.2307/1914185.

Kahneman, D., \& Tversky, A. (1984). Choices, values, and frames. American Psychologist, 39(4), 341-350. http://dx.doi.org/10.1037/0003-066X.39.4.341.

Keller, P. A., \& Block, L. G. (1996). Increasing the persuasiveness of fear appeals: the effect of arousal and elaboration. Journal of consumer research, 22(4), 448-459. http://dx.doi.org/10.1086/209461.

La Tour, M. S., \& Tanner, J. F. j. (2003). Radon: appealing to our fears. Psychology \& 
Marketing, 20(5), 377-394. http://dx.doi.org/10.1002/mar.10078.

Laroche, M., Toffoli, R., Quihong, Z., \& Pons, F. (2001). A cross-cultural study of the persuasive effect of fear appeal messages in cigarette advertising: China and Canada. International Journal of Advertising, 20(3), 297-317.

Leventhal, H. (1971). Fear appeals and persuasion: the differentiation of a motivational construct. American Journal of Public Health, 61(6), 1208-1224. http://dx.doi.org/10.2105/AJPH.61.6.1208.

Lewis, I., Watson, B., Tay, R., \& White, K. M. (2007). The role of fear appeals in improving driver safety: A review of the effectiveness of fear-arousing (threat) appeals in road safety advertising. International Journal of Behavioral and Consultation Therapy, 3(2), 203-222.

Mandel, N., \& Johnson, E. J. (2002). When web pages influence choice: Effects of visual primes on experts and novices. Journal of Consumer Research, 29(2), 235-245. http://dx.doi.org/10.1086/341573.

Miles, A., Rapoport, L., Wardle, J., Afuape, T., \& Duman, M. (2001). Using the mass-media to target obesity: an analysis of the characteristics and reported behaviour change of participants in the BBC's 'Fighting Fat, Fighting Fit' campaign. Health Education Research, 16(3), 357-372. http://dx.doi.org/10.1093/her/16.3.357.

Pratto, F., \& John, O. P. (1991). Automatic vigilance: the attention-grabbing power of negative social information. Journal of personality and social psychology, 61(3), 380-391. http://dx.doi.org/10.1037/0022-3514.61.3.380.

Ringle, C.M., Wende, S., \& Alexander, W. (2005). SmartPLS 2.0. (beta) [Software]. Retrieved July 22, 2011. Retrived from http://www.smartpls.de.

Rogers, R. (1975). A protection motivation theory of fear appeals and attitude change. $\begin{array}{llll}\text { Journal of Psychology, 93-114. } & \text { 91(1), }\end{array}$ http://dx.doi.org/10.1080/00223980.1975.9915803.

Witte, K. (1992). Putting the fear back into fear appeals. The extended parallel process model. Communication Monographs, 59(4), 329-349. http://dx.doi.org/10.1080/03637759209376276.

Witte, K., \& Allen, M. (2000). A meta analysis of fear appeals: implications for effective public health campaigns. Health Education \& Behavior, 27(5), 591-615. http://dx.doi.org/10.1177/109019810002700506.

Witte, K., McKeon, J., Cameron, K., \& Berkowitz, J. (1995). The risk behavior diagnosis scale. Retrieved August 10, 2010, from The Risk Behavior Diagnosis Scale website: https:/www.msu.edu/ wittek/rbd.htm 
Wong, N. C. H., \& Cappella, J. N. (2009). Antismoking Threat and Efficacy Appeals: Effects on Smoking Cessation Intentions for Smokers with Low and High Readiness to Quit. Journal of Applied Communication Research, 37(1), 1-20. http://dx.doi.org/10.1080/00909880802593928.

World Health Organization. (2012). EuroFlu: The WHO European Influenza Network. June 13, 2012. Retrieved from http://www.euroflu.org/

Yi, Y. (1990). Cognitive and affective priming effects of the context for print advertisments. Journal of advertising, 19(2), 40-48. 